\title{
Visual fields in metastatic choroidal carcinoma
}

\author{
RIRI SYLVIA MANOR, YUVAL YASSUR, ITZHAK BEN-SIRA, AND \\ ROBERT BAR-ITZHACK \\ From the Department of Ophthalmology, Beilinson Medical Center, Tel Aviv University Medical School, \\ Petah Tikva, and Assaf Harofe Hospital, Tzrifin, Israel
}

SUMMARY A large choroidal metastasis was diagnosed in the right eye of a 44-year-old man referred for admission to hospital because of 'retinal detachment.' At the same time in the second, symptomless, eye a very small metastasis was observed. Close follow-up during the next month showed an extremely rapid deterioration of visual acuity and visual field in this eye. This is thought to be characteristic of such metastatic tumours in contrast to the slower progress of choroidal malignant melanoma. The application of local radiotherapy to the same eye led to an impressive improvement in the visual acuity and visual field. The source of these bilateral choroidal metastases, which was found only after the patient's death, proved to be a bronchial carcinoma.

The examination of visual fields in patients with metastatic choroidal tumours is usually performed only when symptoms become obvious.

We hereby report a case of histologically proved choroidal metastasis for two reasons: (1) the presence of an advanced choroidal metastasis in one eye as the earliest sign of bronchial carcinoma; and (2) the existence of a small, symptomless metastasis in the other eye; the growth of this metastasis and its subsequent regression after irradiation therapy were followed in static and kinetic studies of the visual fields.

\section{Case report}

A 44-year-old man was referred to the ophthalmological department of Beilinson Hospital with a 2-month history of visual deterioration in the right eye. This had initially been diagnosed by his physician as central serous chorioretinopathy and later as rhegmatogenous retinal detachment. On admission the patient appeared to be in good general health. Visual acuity was counting fingers at $20 \mathrm{~cm}$ in his right eye and $6 / 6$ in his left eye. Ocular movements, intraocular pressure, and refractive media were normal in both eyes. In the right fundus there was retinal and choroidal detachment in the form of 3 high bullae almost touching each other near the optic disc. There was shifting fluid in the third inferior bulla (Fig. 1). The detachment started at

Address for reprints: Dr R. S. Manor, Department of Ophthalmology, Beilinson Medical Center, Petah Tikva, Israel about 3 PD (disc diameters) posterior to the ora serrata, and there was no retinal tear to be seen.

In the left eye, 3 PD above the disc and slightlo $\overrightarrow{0}$ temporal, there was an elevated, yellowish focus oo $0.2 \mathrm{~mm}$ in width looking like a pigment epitheliunow. detachment. Approximately $1.5 \mathrm{~mm}$ of the over lying retina was shallowly detached (Fig. 2). In fluorescein angiography there was a patchy filling of

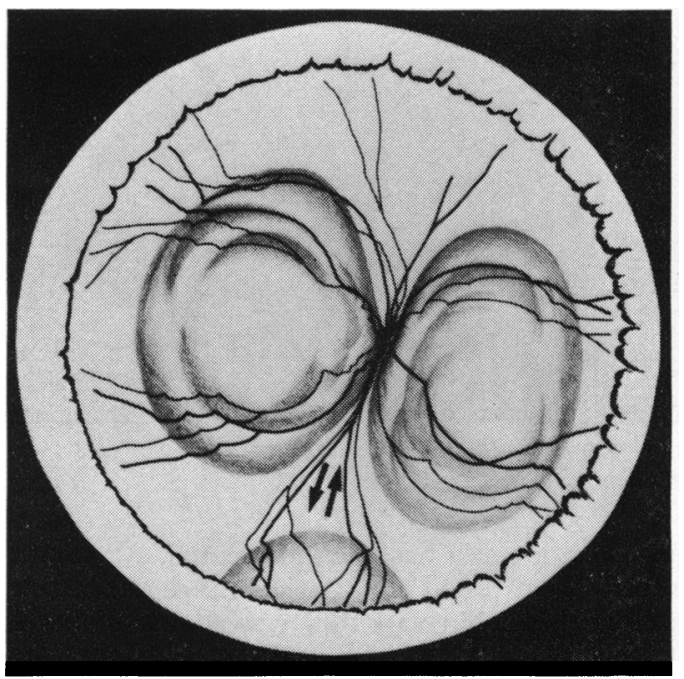

Fig. 113 September 1975. The fundus of the right eye presented 2 high bullae of retinal and choroidal detachment which started a few PD from the ora serrata and almost touched each other near the optic disc. A third inferior bulging area presented shifting fluid 


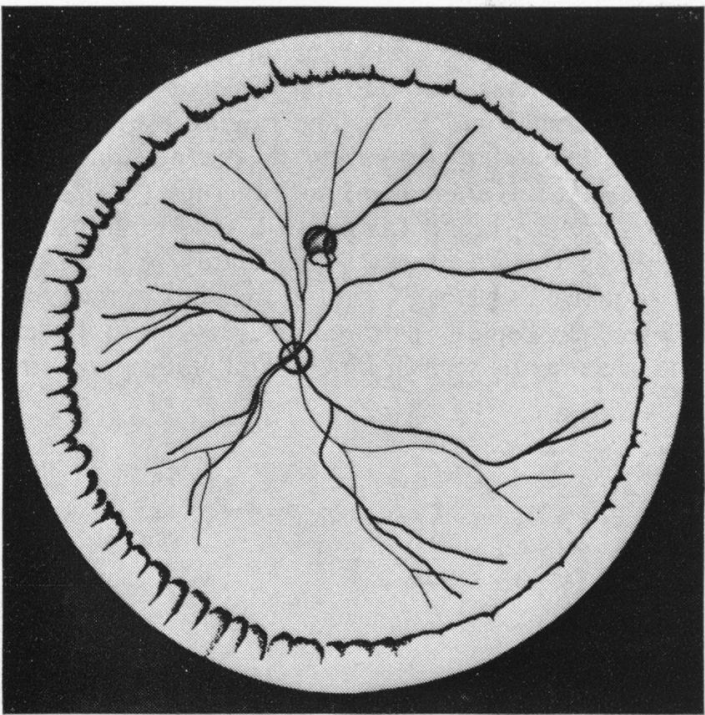

Fig. 213 September 1975. The fundus of the left eye found to harbour in its nasal upper quadrant a very small, elevated, yellowish focus resembling a PE detachment. Approximately 1 PD of the overlying retina was shallowly detached

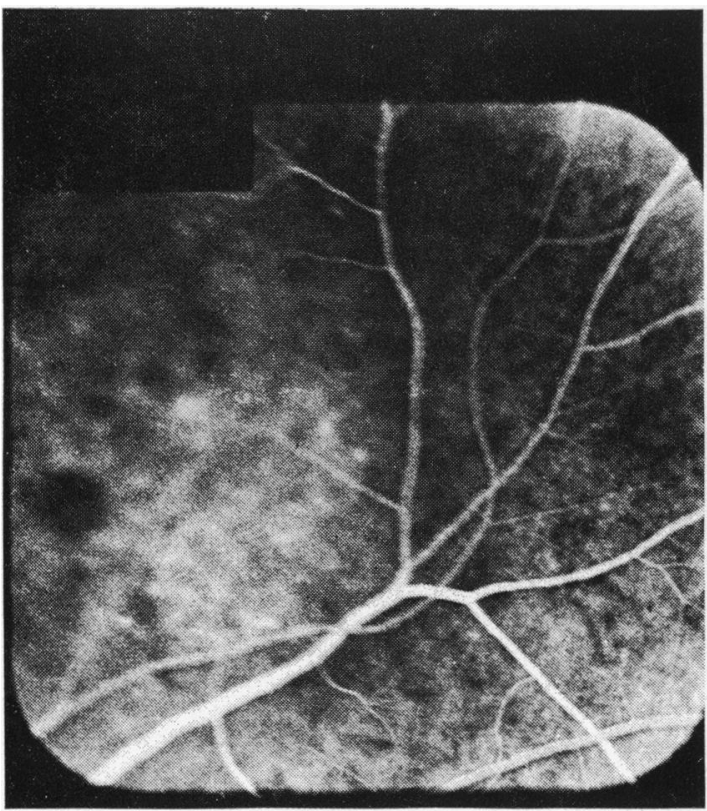

the tumour area with spots of hyperfluorescence and hypofluorescence (Fig. 3). Kinetic visual field examination of the left eye revealed a very dense scotoma in the temporal inferior quadrant (Fig. 4). On static perimetry a depression of the field curve peripheral to the scotoma was also found corresponding to an area in the retina which seemed unaffected on fundus examination (Fig. 5).

In an attempt to discover the primary source of the bilateral choroidal metastases the patient was thoroughly investigated. In the physical examination an enlarged cervical lymph node and hepatosplenomegaly were found. A complete blood count and urine analysis were normal. There was an accelerated erythrocyte sedimentation rate, an increased level of glucose, and a reversed albuminglobulin ratio. The liver function tests gave abnormal results. A liver scan showed an inhomogeneous concentration of radioactive material in both lobes. Brain and thyroid scans were normal. Radiographs of chest, skull, long bones, gastrointestinal tract, and urinary system were all normal.

Biopsy of the enlarged cervical lymph node revealed the presence of an undifferentiated anaplastic carcinoma of unknown origin (Fig. 6). Thus

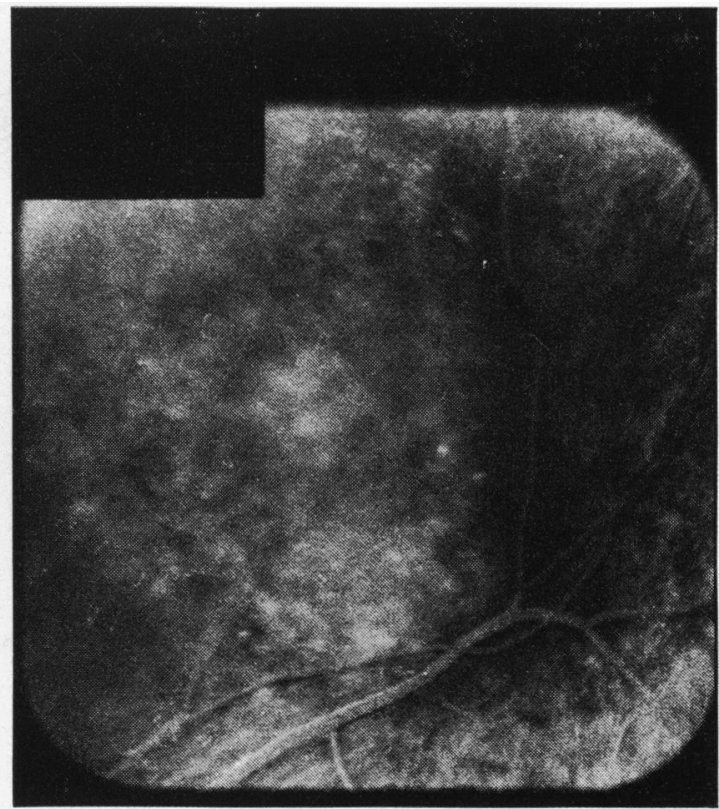

b

Fig. 3 (a) Fluorescein of recirculation phase at $25 \mathrm{~s}$ : patchy filling of tumour area with spots of hyperflourescence and hypofluorescence. (b) Fluorescein of late phase at 5 min: patchy filling of tumour area persists; diffuse leakage, expressed by increased fluorescein staining, along with areas of hypoftuorescence 
the diagnosis of generalised carcinomatosis was confirmed, but there was no evidence of the primary site.

Systemic anticarcinoma treatment was started by the administration of 5-fluorouracil. Four weeks after admission the patient's apparent good health deteriorated and jaundice appeared. There was also a rapid deterioration of visual acuity and the visual field in the left eye. Thus visual acuity, which had been $6 / 6$ on 13 September, the day of admission, dropped to $6 / 10$ with $+2 \cdot 0$ spher. addition (acquired hypermetropia) on 10 October. The visual field, which was studied every few days by static and kinetic perimetry, also showed rapid progression of the scotoma (Figs. 7, 8). The fundal lesion of the lcft eye expanded, extending to the macular area (Fig. 9). At this stage local radiotherapy $(1,000$ rads weekly for 3 weeks) was applied. One month after beginning this treatment visual acuity in the right eye improved to $1 \mathrm{~m} \mathrm{FC}$ and in the left eye returned to 5/6. There was also a dramatic regression in the left field scotoma as seen in kinetic and static perimetry
Fig. 4 I3 September 1975. The visual field of the left 'good' eye, demonstrating the presence of $a$ very dense scotoma in the temporal inferior quadant

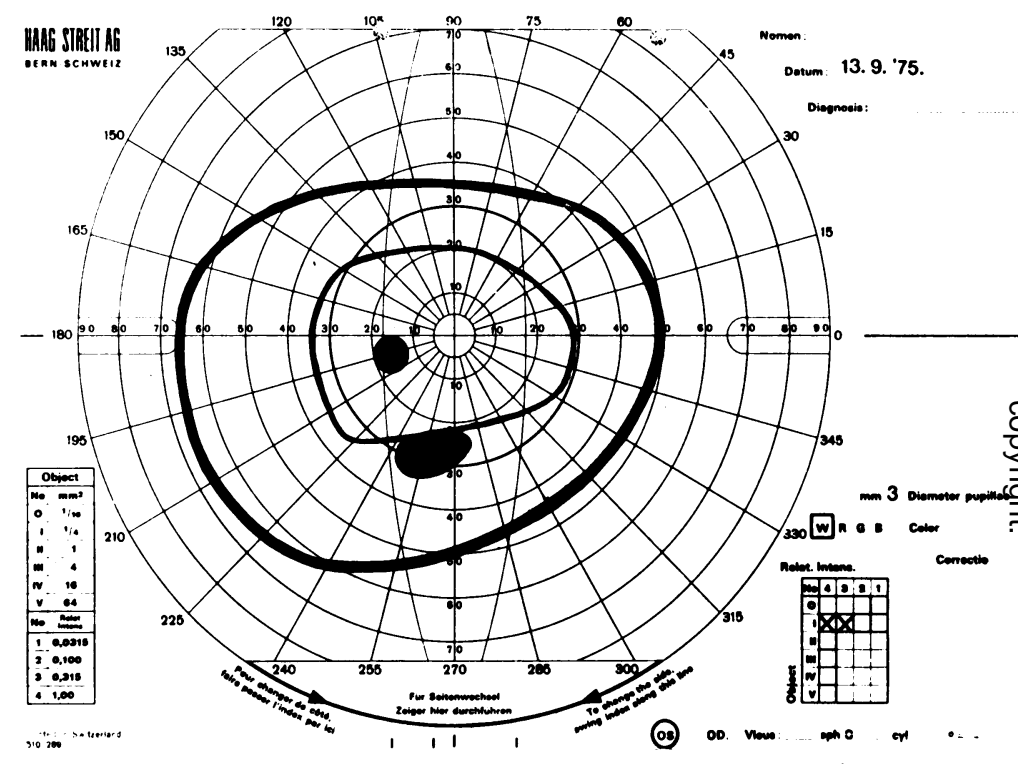

Fig. 513 September 1975. Left eye: static perimetry (profile $225-75^{\circ}$ ) showing temporally the sudden drop of the curve at $22^{\circ}$ and its gradual descent from $50^{\circ}$ to $30^{\circ}$. This defect may be related to the metastatic tumour, which gave an absolute scotoma and to the surrounding detachment, which gave a relative, gradual depression of acuity curve 
(Figs. 10, 11). At the same time the ophthalmoscopic picture showed a regression of the exudative retinal detachments in both eyes. However, after 2 months in hospital and just 2 days after the above visual field examination, the patient died of generalised carcinomatosis.

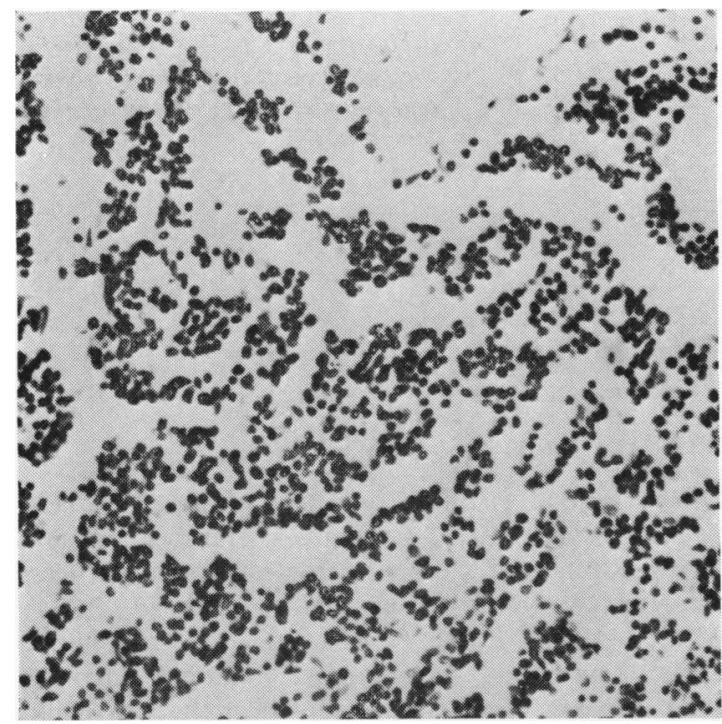

Fig. 6 Cervical lymph node biopsy. The lymph node tissue was replaced by tumour tissue composed of small hyperchromatic nuclei with scanty cytoplasm. $H$ and $E$ 200
PATHOLOGICAL FINDINGS

The primary tumour was found to be undifferentiated bronchical carcinoma, small-cell type, located in the apex of the right lung (Fig. 12). There were widespread metastases in the liver, adrenal glands, pleura, stomach, kidneys, thyroid, paratracheal and parapancreatic lymph nodes, leptomeninges, and hypophysis. Bile stasis in the liver and acute pancreatitis were also found.

GROSS AND MICROSCOPIC

OCULAR EXAMINATION

The eyes were carefully studied with a clinicopathological correlation in view. In the right eye a brownish mass was observed under the retina at the posterior pole. In the left eye a $3 \mathrm{~mm}$ brownish tumour was found under the retina at the upper nasal quadrant slightly above the optic disc (Fig. 13).

The histological examination of the right eye showed the tumoral mass to be composed of extremely anaplastic cells with hyperchromatic nuclei and scanty cytoplasm arranged mainly round choroidal vessels (Fig. 14). Numerous necrotic cells and empty areas were present owing to destruction of cells (Fig. 15). Choroidal vessels showed thickening of the walls, and some of them were obstructed. The retinal pigment epithelium was seen to have reacted either by hyperplasia or by drusen formation. The subretinal fluid was coagulated.

Histological examination of the tumour in the left eye showed the same cellular characteristics described above. At the site of the tumour there was

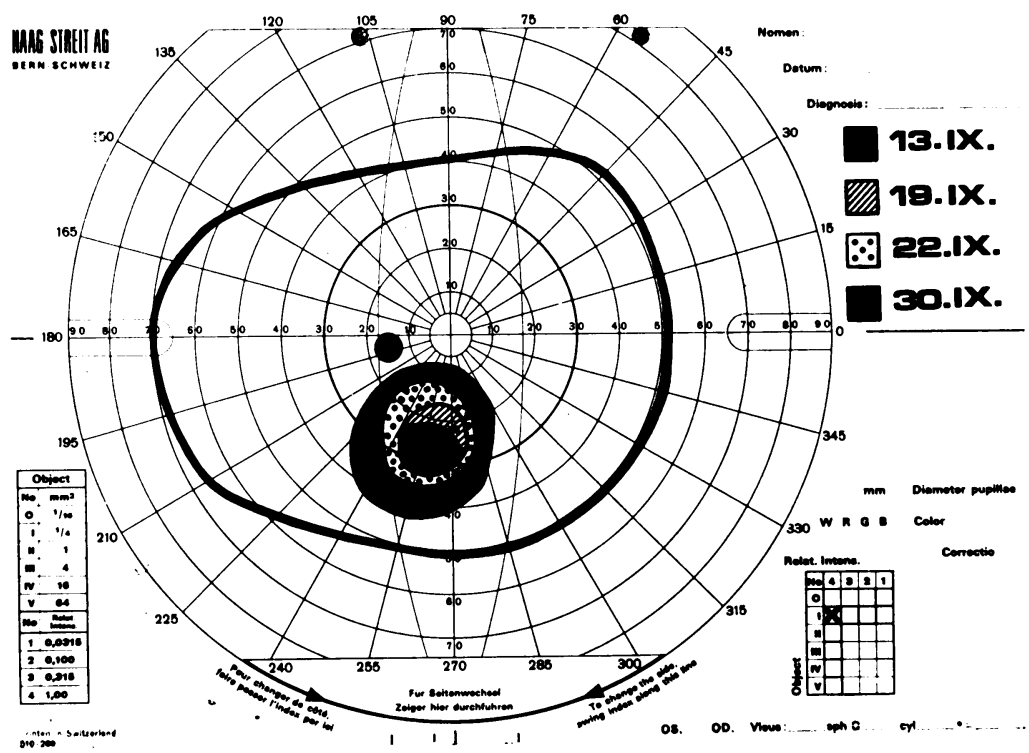

Fig. 7 Rapid enlargement of the absolute scotoma from 13 to 30 September 


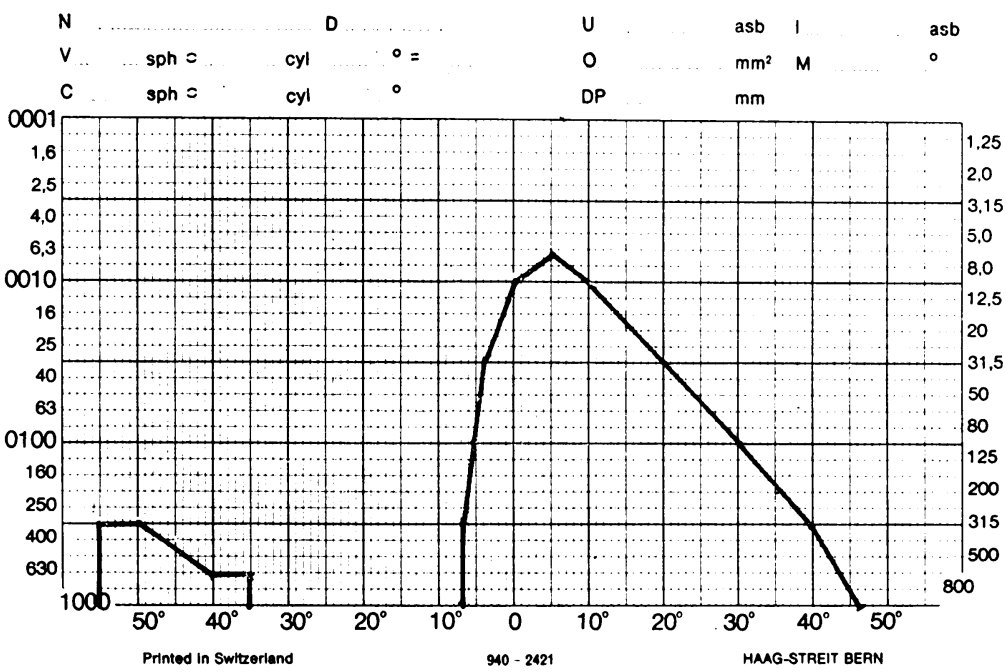

Fig. 810 October 1975. Static perimetry of $225-75^{\circ}$ showing the presence of a central scotoma and complete deterioration of the temporal field chorioretinal adhesion and round it a flat retinal detachment (Fig. 16).

\section{Discussion}

Metastatic carcinoma of the eye has been found to be bilateral in $4.4 \%$ to $30 \%$ of all such cases in reported series (Albert et al., 1967; Bloch and Gartner, 1971; Casanovas, 19ó6; Cordes, 1944; Duke-Elder and Perkins 1966; Ferry and Font,

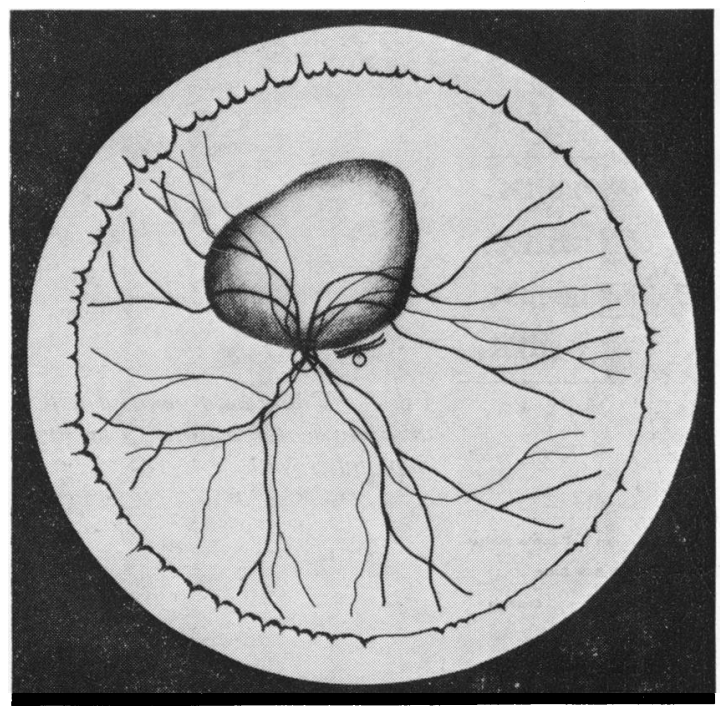

Fig. 910 October 1975. The drawing of the left fundus shows the rapid extension of the initially very small metastatic tumour
1974; François et al., 1976; Haye and Calle, 1972; Yaeger et al., 1971). Recently a number of new cases of bilateral choroidal metastases have been reported (Asayama et al., 1974; Fu et al., 1974; Walker, 1974). Reese (1963), on the other hand, pointed out that simultaneous bilateral involvement appears very seldom. However, it is possible for a small metastasis in the second eye to be overlooked. Therefore it may be of value, when possible, to perform a careful bilateral visual field examination in such patients to detect early signs of metastasis, i.e., the presence of scotomas. Furthermore, successive visual field studies, in addition to other ophthalmological examinations, may be helpful in making the differential diagnosis between metastatic carcinoma and malignant melanoma. As is well known, even the fluorescein angiography pattern of choroidal metastasis is often indistinguishable from that seen in choroidal melanomas and haemangiomas (Davis and Robertson, 1973). With malignant melanoma the rate of growth of the tumour and the visual field progression are usually slower (Hogeweg et al., 1976). The accurate differential diagnosis may serve to avoid unnecessary enucleation in metastatic carcinoma. Furthermore, when the eye symptoms are the presenting signs of carcinomatosis, the correct diagnosis will lead to the proper approach, including a general check-up.

The rapid deterioration in visual acuity and visual fields in choroidal metastasis is exemplified by our case also. During the period of 1 month the weekly examinations showed an impressive change in visual fields which was paralleled by an obvious extension of the choroidal metastases.

The beneficial effect of irradiation treatment on 
choroidal metastatic lesions has been amply documented (Gillet, 1971; Casanovas, 1966; Haye and Calle, 1972; MacMichael, 1969; Reese, 1963; Walker, 1974; Yaeger et al., 1971). In our case also the regression of the fundal lesion after irradiation therapy was reflected in the improvement of visual acuity and visual fields.

Another point of interest in this case is the fact that the intraocular metastases were the first sign of generalised carcinomatosis. Also worth noting is the fact that the source of metastatic embolisation was not found before death. Ferry and Font (1974) found that the most common cause of ocular metastasis was breast carcinoma but that, when the ocular metastasis was the presenting sign, the commonest source of it was bronchial carcinoma. In cases in which the primary tumour cannot be identified during life this statistically valuable finding may be helpful in predicting the site of the primary tumour.
Fig. 1019 November 1975. The visual field of the left eye, the scotoma involving the temporal lower quadrant after local radiotherapy showing a dramatic regression of
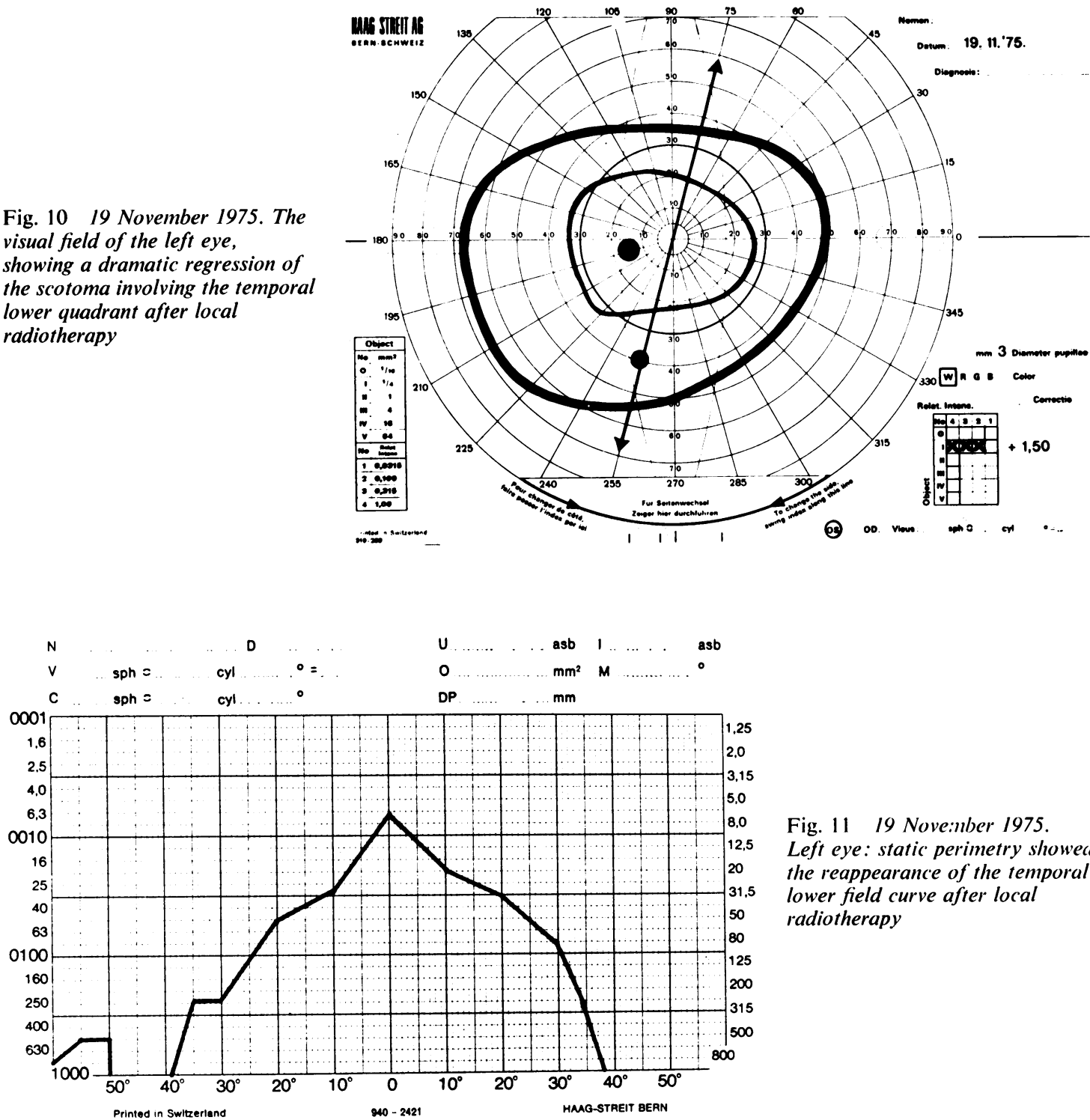

Fig. 1119 Nove:nber 1975. Left eye: static perimetry showed the reappearance of the temporal lower field curve after local radiotherapy 


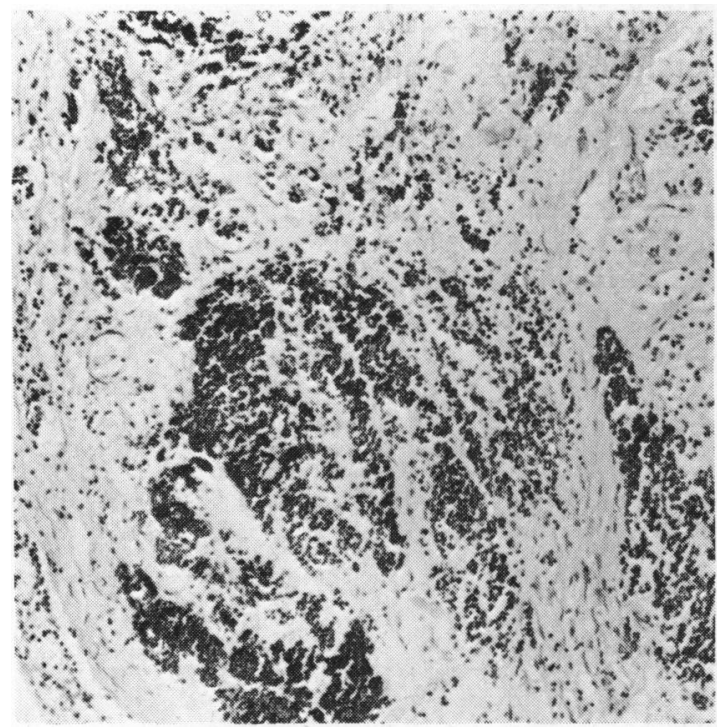

Fig. 12 Bronchus of the upper pole of the right lung, showing tumour mass composed of anaplastic small cells arising in bronchial mucosa and penetrating into lung parenchyma. $H$ and $E \times 120$ )

Fig. 14 (right) Tumoral cells in the choroid of the right eye. These were very anaplastic cells with hyperchromatic nuclei and scanty cytoplasm arranged mostly around choroidal vessels. $(H$ and $E \times 440)$

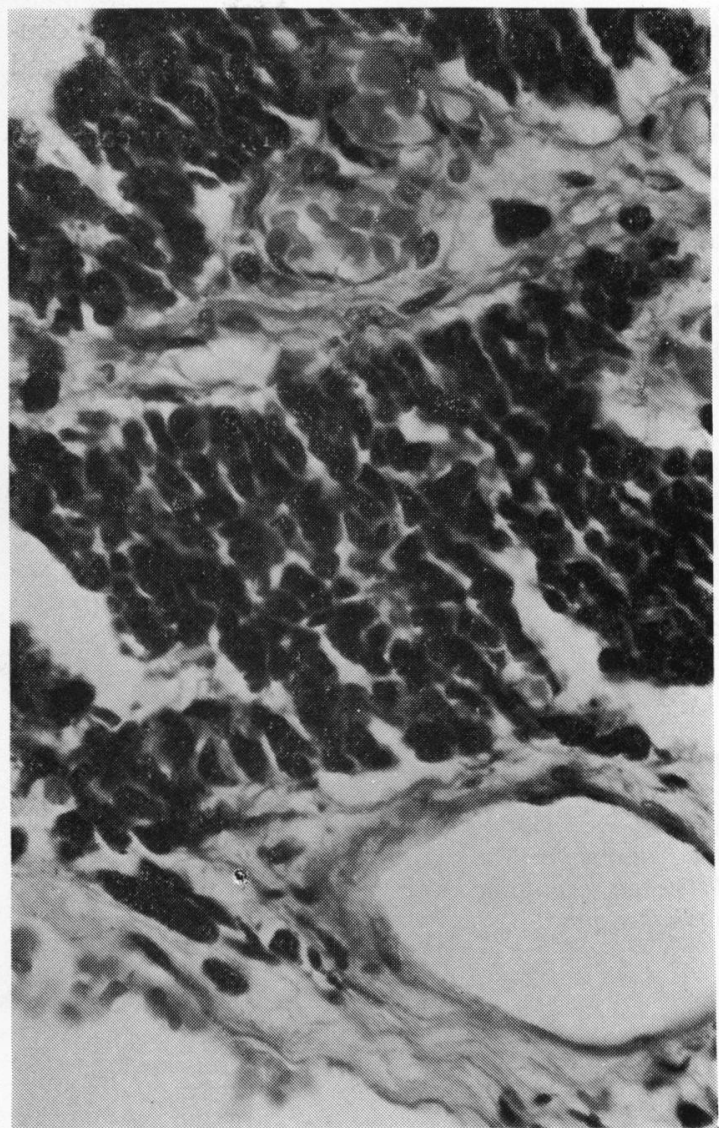

Fig. 13 Left: the horizontal section of the right eye. Tumour mass occupies the posterior pole of the eye, detaching the retina Right: the oblique section of left eye (upper temporal-lower nasal plane), tumour mass detaching the retina 


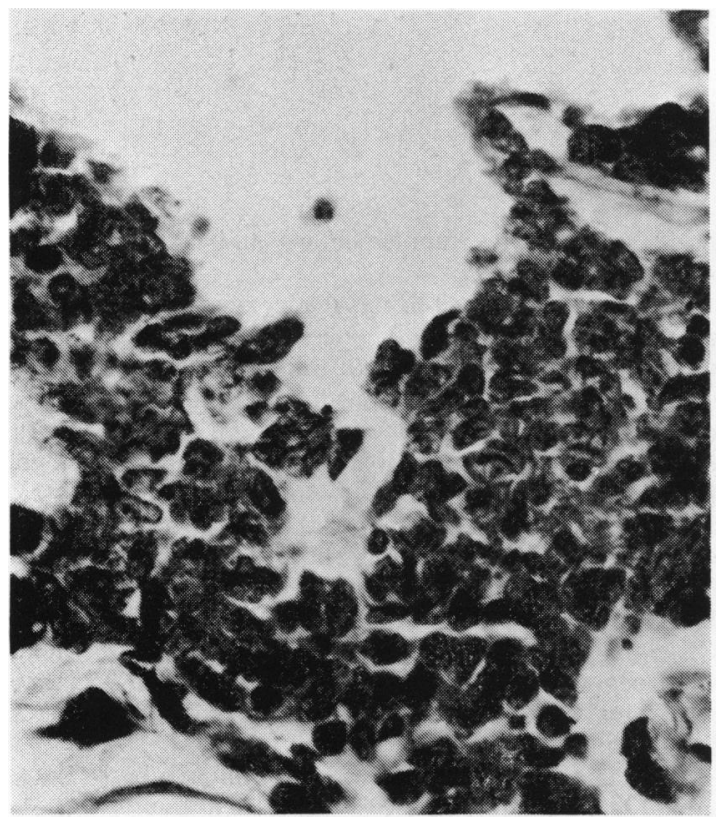

Fig. 15 Numerous necrotic cells and empty areas due to destruction of cells were evident in this preparation of the right eye. $(H$ and $E \times 160)$

\section{References}

Albert, D. M., Rubinstein, R. A., and Scheie, H. G. (1967). Tumor metastasis to the eye. I. Incidence in 213 adult patients with generalized malignancy. American Journal of Ophthalmology, 63, 723-733.

Asayama, K., Uyama, M., and Nabeshima, Y. (1974). A case of metastatic carcinoma of the choroid simulating malignant choroidal melanoma. Folia Ophthalmologica Japonica, 25, 1306-1312.

Bloch, R. S., and Gartner, S. (1971). The incidence of ocular metastatic carcinoma. Archives of Ophthalmology, 85, 673-675.

Casanovas, J. (1966). Tumeurs metastatiques de l'oeil et de l'orbite. Ophthalmologica, 151, 272-283.

Cordes, F. C. (1944). Bilateral metastatic carcinoma of the choroid with $x$-ray therapy to one eye. American Journal of Ophthalmology, 27, 1355-1370.

Davis, D. L., and Robertson, D. M. (1973). Fluorescein angiography of metastatic choroidal tumors. Archives of Ophthalmology, 89, 97-99.

Duke-Elder, S., and Perkins, E. S. (1966). System of Ophthalmology, Vol. 8, p. 917. Henry Kimpton: London.

Ferry, A. P., and Font, R. L. (1974). Carcinoma metastatic to the eye and orbit. I. A clinico-pathologic study of 227 cases. Archives of Ophthalmology, 92, 276-286.

François, J., Hanssens, H., and Verbraeken, H. (1976). Intraocular metastasis as first sign of generalized carcinomatosis. Annals of Ophthalmology, 8, 405-419.

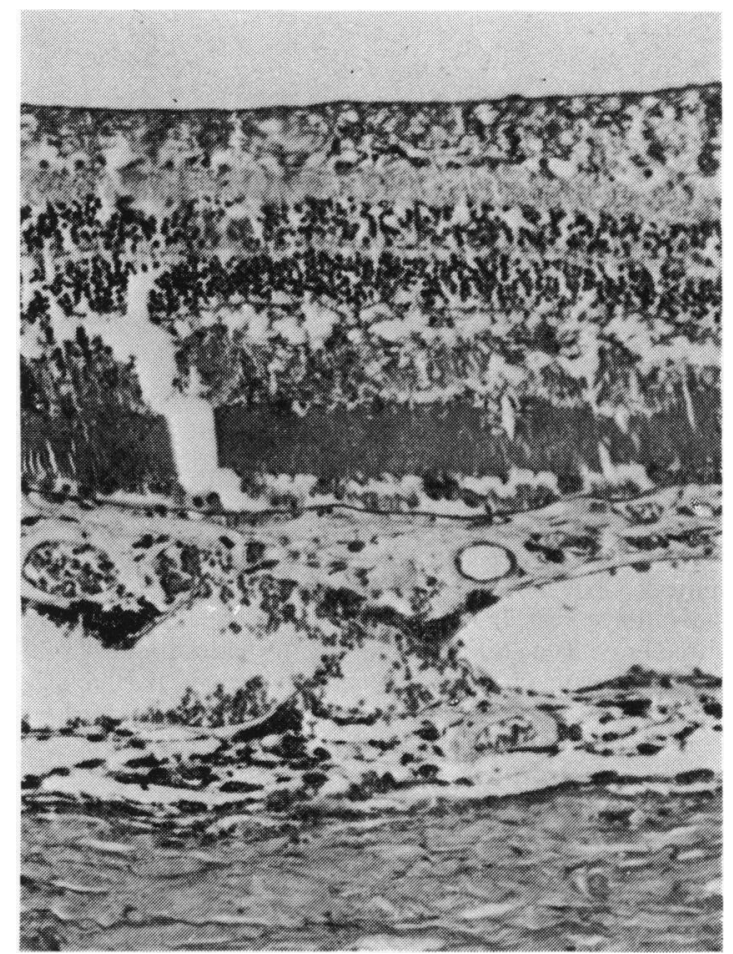

Fig. 16 The tumour of the left eye showed the same cellular characteristics. A flat retinal detachment is observed round the tumour. ( $H$ and $E \times 120$ )

Fu, Y. S., McWilliams, N. B., Stratford, T. P., and Kay, S. (1974). Bronchial carcinoid with choroidal metastasis in an adolescent. Cancer, 33, 707-715.

Gillet, R. B. (1971). Metastatic carcinoma of the choroid. Te ras Medicine, 67, 72-75.

Haye, C., and Calle, R. (1972). Tumeurs metastatiques choroidiennes. Annales D'Oculistique, 205, 549-555.

Hogeweg, M., Bos, P. J. M., Greve, E. L., and De Haan, A. B. (1976). Malignant melanomas of the choroid that on fluorescein angiography and perimetry gave the impression of naevi. Document Ophthalmologica, 40, 301-318.

MacMichael, I. M. (1969). Management of choroidal metastases from breast carcinoma. British Journal of Ophthalmology, 53, 782-785.

Reese, A. B. (1963). Tumors of the eye. 2nd edn., p. 514. Paul B. Hoeber: New York.

Walker, C. (1974). Bilateral choroidal metastases from 'adenoma' of the bronchus. British Journal of Ophthalmology, 58, 625-629.

Yaeger, E. A., Frayer, W. C., Southard, M. E., et al. (1971). Effect of radiation therapy on metastatic choroidal tumors. Transactions of the American Academy of Ophthalmology and Otolaryngology, 75, 94-101. 